\title{
El mundo, la psique y la urbe en Tsutomu Nihei. Una reflexión dialógica
}

\author{
World, Psyche and City in Tsutomu \\ Nihei. A Dialogical Reflection
}

\section{Pau González Gost}

Pau González Gost trabaja como profesor de filosofía en un instituto de secundaria. Es doctor en Lenguas y literaturas modernas con una tesis sobre la extrañeza del sujeto moderno que pone en relación a autores como Le Guin, Asimov, Pessoa o Poe. Ha publicado anteriormente en CuCo, Cuadernos de cómic.

Fecha de recepción: 7 de enero de 2019

Fecha de aceptación definitiva: 28 de enero de 2020 


\title{
Resumen
}

Reflexión sobre el mundo de Blame! del autor japonés Tsutomu Nihei poniéndolo en relación con la obra de algunas autores filosóficos contemporáneos; sobre todo Claude Parent. En el diálogo entre autores se busca una nueva interpretación de la obra que nos permita ver más allá de sus ambiciones cyberpunk y de crítica social, para imaginarnos que posee también una rica dimensión psicológica que explorar.

Palabras clave: Cyberpunk, filosofía, Nihei, Parent, psicología

\begin{abstract}
Reflection on the world of Blame! of the japanese author Tsutomu Nihei putting it in relation to the work of some contemporary philosophical authors; especially Claude Parent. The dialogue between authors looks for a new interpretation of the work that will allow us to see beyond cyberpunk ambitions and social criticism, to imagine that it also possesses a rich psychological dimension to be explored.
\end{abstract}

Keywords: Cyberpunk, Nihei, Parent, Philosophy, Psychology

\section{Cita bibliográfica}

González Gost, P. «El mundo, la psique y la urbe en Tsutomu Nihei. Una reflexión dialógica», en CuCo, Cuadernos de cómic, n. o 14 (2020), pp. 110-119. 
La obra Blame! de Tsutomu Nihei está ambientada en un mundo posapocalíptico en el que prácticamente todo el territorio es una urbe llena de estructuras deshabitadas. Los habitantes de este mundo son mayoritariamente seres artificiales. Los grandes edificios jamás terminan. Quedan algunos humanos, pero muy pocos. El protagonista es un ser artificial con apariencia humana que trabaja para el gobierno (un gobierno difuso en guerra contra otros grupos de poder). Su nombre es Killy. Está buscando unos genes de conexión a la red pero no sabemos muy bien por qué ni qué son exactamente. Suponemos que sirven para encontrar algún tipo de información anterior al apocalipsis que acabó con casi todo, pero no podemos estar muy seguros. El protagonista se va enfrentando a monstruos y a otros seres artificiales que intentan impedir que consiga lo que está intentando. Estos monstruos trabajan para grupos contrarios al gobierno. Las batallas son continuas y se combina el recorrido por una ciudad infinita (las construcciones jamás terminan) con las luchas a muerte con diferentes monstruos. La obra propone un recorrido ascendente por el mundo-ciudad (ya hemos dicho que las construcciones nunca terminan, por lo tanto el mundo que explora el protagonista es una continua construcción), de forma que se mezcla una historia de búsqueda de un objeto perdido con un camino de descubrimiento interior. Es decir: como en muchas historias de búsqueda de un objeto externo, la verdadera búsqueda es algo que el personaje descubre en su interior.

El mundo de Nihei se aparece como una urbe, pero también como una psique. La ausencia de ausencia representa el lleno de una construcción que es a la vez destrucción. En su movimiento incesante, en su viaje sin fin, el pasajero-protagonista descubre que ya no queda casi nada de lo bumano, a la vez que descubre la humanidad en sí mismo y en el mundo. El mundo es «urbano, demasiado urbano»: «... nuestra vida entera transcurre en las prótesis de los viajes acelerados, de los que ya ni siquiera tenemos conciencia... "la necesidad de peregrinación ha terminado por colocar la fijeza de la vida en el desplazamiento"». ${ }^{1}$ Lo único fijo que hay en la vida del protagonista es aquello que se mueve: su cuerpo, las máquinas que usa para desplazarse, la búsqueda incesante... Es una línea de fuga entre líneas de fuga. Es una función matemática que tiende al infinito. Moviéndose entre arquitectura de pesadilla, habitando los más radicales sueños de la razón goyescos, recordando las construcciones invisibles que se desprenden del urbanismo actual, hijo de la acumulación y de la circulación de capital. El «dolor existencial de una crisis agónica de la vida cotidiana de la ciudad» $»^{2}$ se multiplica exponencialmente hasta romper todo resto de humanidad. El mundo-ciudad es el

1 Virilio, P. Estética de la desaparición. Barcelona, Anagrama, 1988, pp. 68-69.

${ }^{2}$ Harver, D. Ciudades rebeldes. Del derecho de la ciudad a la revolución urbana. Madrid, Akal, 2013, p. 6. 
paradigma de la deshumanización posmoderna, pero es en esa deshumanizada ciudad donde Killy se humaniza. Desolación exterior que refleja la interioridad del individuo moderno: devastada e hiperconstruida para llenar hasta el último espacio vacío; no sea que el vacío nos recordara la ausencia, la muerte, es decir: nuestra propia limitación y humanidad abocada a la desaparición. Pero esa hiperconstrucción también abre vacíos y grietas: las calles, los espacios interiores, los abismos... La fuga del vacío crea las condiciones para que se generen vacíos en un movimiento paradójico ad infinitum.

Desde lo poshumano se articula un recorrido que se desliza en el mundo con indiferencia, instalado en la soledad y la desesperanza. Aun así, hay algo que mantiene al protagonista dispuesto a seguir caminando. Esa motivación casi imposible que interroga a todo aquel con el que se cruza: «busco genes de conexión a la red». Killy, marioneta cyberpunk cuyos hilos se han convertido en telaraña, en lucha contra monstruos lovecraftianos que recuerdan a la espuma de poliuretano. Su aparición en medio de las ciclópeas urbes refleja el «repugnante caos engendrado por el frenético capital urbanizador globalizado». ${ }^{3} \mathrm{El}$ mundo-urbe se hace eco de las megalópolis y del desarrollismo basado en bloques de hormigón. Pero, además, nos recuerda que el mundo es un "constructo», ya que la ciudad es también discurso construido en el intercambio violento de intereses enfrentados. Y el mundo-psique es un laberinto del que nos hemos desconectado, incapaces de acceder a él, una parte de nosotros vaga perdida en su interior.

El urbanismo va a la deriva, la arquitectura se desplaza sin cesar, la vivienda es tan solo la anamorfosis de un umbral. [...] La arquitectura no mora en la arquitectura sino en la geometría, en el espacio-tiempo de los vectores; la estética de lo edificado se disimula en los efectos especiales de la máquina de comunicación. ${ }^{4}$

En este Hades geométrico se produce la deriva del protagonista hacia su destino. É1 es una máquina de comunicación: hecho para conectarse a la red y encontrar genes de antes de la epidemia. Él oculta la estética de las edificaciones con las cortinas de humo provocadas por los efectos especiales de su pistola y en la representación de un humano demasiado artificial. Aunque Faustino Cordón nos haya señalado que la creación de un medio artificial es lo que nos permitió evolucionar mucho más rápido que las demás especies, por lo que la artificialidad parece ser una de las características de la humanidad. Visto así, el protagonista es una metáfora de los seres humanos: buscando la trascendencia (conectarse a algo más grande que él) en un viaje que no termina sino con la muerte.

La velocidad del transporte multiplica la ausencia. Antaño se le recomendaba al neurasténico viajar para olvidar, viajar paliaba la tentación de suicidio oponiéndole un sustituto: la

\footnotetext{
${ }^{3}$ Ibid. p. 14.

${ }^{4}$ Virilio, P. Op. cit., pp. 73-74.
} 
pequeña muerte de las partidas, la rapidez del desplazamiento equivale ahora a la desaparición en la fiesta sin mañana del viaje y significa, para cada uno, una suerte de repetición en diferido de su último día. ${ }^{5}$

En la obra, parece que el motivo del viaje es la recuperación de una memoria anterior al (casi) exterminio de la humanidad, por lo que el desplazamiento sirve para recordar el día en que todo terminó. Vagando por el mundo posapocalíptico, el apocalipsis acecha a la vuelta de la esquina en forma de ausencia. Por lo que el fin de los días, los últimos días, son los días por los que discurre el espacio-tiempo de la historia. La sensación de repetición, de bucle ambiental e incluso emocional, se consigue con la expresión del personaje y con los espacios que va pisando, que sin ser el mismo siempre son el mismo. Aunque el viaje no es rápido, pero tampoco lo necesita ya que la peregrinación es constante y el peligro de la ultraviolencia de los monstruos que se aparecen nos recuerda la velocidad de las máquinas de guerra. El protagonista desaparece engullido por una superestructura (a nivel simbólico e imaginal) y la fiesta a la que se ve arrojado es una pesadilla sin posibilidad de amanecer.

El despertar no es más que un vano recuerdo y se deben seguir recorriendo las estructuras subconscientes hasta que el individuo sea derrotado por la violencia del edificio $\sin$ fin. El yo ha sido absorbido por la sombra junguiana y vaga buscando una salida que puede ser que no exista. Es desde esta perspectiva psicológica que podemos interpretar el final del cómic como un despertar: el sujeto en crisis se dirige hacia la mónada (símbolo de individuación), atravesando el agua (símbolo del subconsciente), llegando a un espacio fronterizo (símbolo del contacto entre consciencia e inconsciencia)... El camino del guerrero ha sido una suerte de narrativa interna para hacer frente a la deshumanización y a la propia monstruosidad: la protección de los amigos, la destrucción y el ataque a aquellos que comercian con cuerpos. Todo apunta a la búsqueda de una cierta dignidad basada en la resistencia: el androide genéticamente modificado se niega a perder su ética, su individuación lo dirige a no convertirse en hombre-masa para así mantener una cierta perspectiva que no se deja arrastrar por el nihilismo más sombrío que habita en todos los rincones del mundo de Nihei.

No se han estudiado suficientemente las causas profundas de la evolución general de la tecnología: la miniaturización, reducir a nada o casi nada el tamaño de los aparatos, implica no solo suministrar piezas de recambio para el organismo al ponerlas a escala del cuerpo humano sino, también, crear en el interior del individuo una rivalidad parasensible, un desdoblamiento del ser en el mundo. ${ }^{6}$

Cuando esta tecnología se convierte en tecnología genética y es capaz de replicar el cuerpo humano entonces se produce un replicarse, un desdoblamiento reflexivo

\footnotetext{
5 Idem.

${ }^{6}$ Ibid., pp. 75-76.
} 
que crea a un otro. Dicho replicarse parece ser metáfora de esta rivalidad interior, este enemigo interno o este otro creado por la tecnología y que el ser humano ha llevado siempre en su interior. En la posmodernidad parece que el hombre ha tomado consciencia de que se estaba produciendo a sí mismo en su interior a partir de la tecnificación de la mente y del cuerpo. Esta tecnificación puede ser entendida en términos de pesadilla o de sueño "posibilitador». Este desdoblamiento, en Nihei, se expresa en términos de arquitectura genética, aunque cada época lo ha expresado a su manera. Killy es el Otro de la humanidad, pero es también un otro interior en un inframundo psíquico. Es la figura de la Sombra junguiana moviéndose en el interior de ella misma, buscando una salida para comunicarse con la conciencia. Ella se ha atrapado en ese laberinto de arquitecturas sobredimensionadas, perdida en una cárcel subconsciente infinita. Condenada a vagar por «la sobredimensión de las ciudades» observando «el carácter anárquico de su crecimiento». ${ }^{7}$

De ese modo asistimos a la función de desplazamiento de la máquina psíquica. Función propia de la modernidad y de su suelo resbaladizo que se consolida en la posmodernidad como forma de resistencia y/o de supervivencia. Este desplazarse necesita ir salvando obstáculos, aunque estos en el mundo-ciudad son continuos ya que «crear un recinto implica fijar un obstáculo al recorrido». ${ }^{8}$ Por lo tanto es un recorrido continuamente interrumpido. No hay fluidez. El capitalismo solo da fluidez al capital y la psique escindida (conciencia e inconciencia son incapaces de comunicarse) tampoco puede fluir, por eso aparece un capital psíquico desbocado, función libídica ero-tanática, representada en los monstruos; como explosiones puntuales para liberar todo ese potencial que de otro modo destruiría el organismo psíquico y/o social. Pero aunque no haya fluidez sí que hay circulación: «la "Circulación" ha nacido y lo ha hecho DIsOcIADA del habitar». ${ }^{9}$ Esta disociación es la expresión de una pérdida de sentido fundamental, de un catapultarse a través de la ratio hacia la arquitectura inversa de sí misma. Las estructuras irracionales demuestran la disociación entre el habitar y el circular. Digo que la demuestran porque la mayor expresión de la disociación es la locura: la rotura de la propia sujeción, es decir, del sujeto. «La enfermedad es movimiento: sufrimiento orgánico, tensión, combate». ${ }^{10}$ No hay posibilidad de síntesis. La escisión es marca de la época. La modernidad puso el fundamento de esta disociación y la posmodernidad la ha afianzado. El sujeto es locura, desgarro y alejamiento continuo de sí mismo. «El suelo ya no se utiliza para su función básica, habitar-vivir; sino para responder a una idea que nace como constricción: circular, ser canalizado». ${ }^{11}$ El protagonista es canal, canal de acceso a la red, médium de aquello que está más

\footnotetext{
7 Parent, C. Vivir en lo oblicuo. Barcelona, Gustavo Gil, 2009, p. 10.

8 Ibid., p. 8.

9 Ibid., p. 9.

${ }^{10}$ Morey, M. Lectura de Foucault. Madrid, Sexto Piso, 2014, p. 137.

${ }^{11}$ Parent, C. Op. cit., p. 14.
} 
allá de sí mismo: las estructuras de la ciudad-mundo; expresión de la locura posmoderna. Killy, más allá de ser el protagonista, cumple otra función: la de presentador de un mundo, de otro mundo que intuimos subterráneo en el sentido de que nace en el inconsciente colectivo; instancia inexistente que simplemente es depositaria de todas las ficciones desechadas de la ficción colectiva realmente aceptada; ficción de ficciones que aglutina y engulle todo aquello que queremos que quede a la sombra de nuestra gran ilusión consensual.

«Las ciudades horizontales se ahogan porque su estructura se extiende más allá de unos límites concebibles; las ciudades verticales por haber desintegrado la trama urbana». ${ }^{12}$ Killy se mueve entre el ahogo de las ciudades horizontales y la desintegración de las ciudades verticales. De hecho, la caída final dentro del agua es metáfora también del ahogamiento producido por la vida urbana moderna. El apocalipsis ha llegado en forma de construcción infinita. Como ya hemos visto, a priori no hay espacios vacíos en la psique-mundo de Blame!, por lo que no hay posibilidad de diálogo interno ni externo; pero este horror vacui está contestado por las propias grietas que abre la ciudad en su construirse: calles, abismos e interiores permiten que el protagonista pueda dialogar y tender puentes. Además, nos encontramos con una cierta intención de estructura oblicua en el sentido de Parent, es decir, de hacer habitable aquello que hemos convertido en inhabitable; por eso el circular se convierte en el habitar, y la habitación se realiza en circulación, salvando obstáculos.

\begin{abstract}
Sensibilizado de forma mucho más intensa, el cuerpo participa de la sensación de gravedad. Sobre una pendiente, el hombre percibe su propio peso de forma más evidente, incluso estando inmóvil, ya que es necesario realizar mecánicamente un esfuerzo muscular para estar en equilibrio. El hecho de ser conscientes del propio cuerpo, incluso estando inmóvil, se intensifica todavía más cuando uno se desplaza sobre las rampas. El peso se convierte en un motor interno. Al descender por una pendiente se desencadena una aceleración, se utiliza el peso del cuerpo en el sentido de una pérdida de equilibrio constantemente controlada; subir por una rampa corresponde a una retención, a una ralentización del recorrido. Las sensaciones de euforia (descender) y de esfuerzo (ascender) se asocian automáticamente al tipo de recorrido por el que se ha optado. ${ }^{13}$
\end{abstract}

Continuamente estamos ascendiendo y descendiendo en el manga de Nihei. Como si de una katabasis interminable se tratara. Un bajar y un subir en bucle que no termina. Incluso la estructura de la obra en sentido ascendente (el ir subiendo niveles) tiene su contrapunto en la caída final, el gran descenso que niega los anteriores ascensos. Aunque el descenso final sí que tiene algo de definitivo, como si fuera una muerte y un renacimiento. En la historia «se produce un permanente intercambio energético entre el cuerpo del hombre y su soporte. El cuerpo se convierte en un POTENCIAL DE

${ }_{12}$ Ibid. p. 11.
${ }^{13}$ Ibid. p. 21. 
ENERGÍA»; ${ }^{14}$ hay una tensión continua entre el cuerpo y la estructura urbana por la que se desplaza. Es potencial de transformación de aquello que recorre, aunque sea destructivo y explosivo. Es una energía que tiene intención de recomponer la multiplicidad caótica que supone haber llegado a una Unidad Estructural, y para ello tiene que encontrar brechas, agujeros, formas de recorrido que contradigan la estructura que se va encontrando.

Nunca insistiremos bastante en lo que supone una ELECCIón PERMANENTE de recorrido que se oponga a la canalización forzada de los hombres (calle, ascensor, pasillo...); se trata del primer paso hacia una libertad recobrada, tanto en las estructuras urbanas como en los espacios del habitar. ${ }^{15}$

Por lo que hay también una afirmación libertaria delante de la imposición del cosmos-urbe con todo lo que supone: jerarquía, violencia institucional, esclavitud, precariedad... El viaje de Killy es un viaje libertario en el sentido de que busca elegir continuamente su propio recorrido, y cuando la propia estructura urbana le impide avanzar hacia las direcciones que él desea destruye paredes y monstruos para continuar con su elección. No se deja canalizar, él es canal de acceso a la red, es canal de memoria y es posibilidad de síntesis. Figura humana (aunque no sea humano) moviéndose por un espacio de pesadilla cyberpunk, lleno de escaleras y de ascensores que se confunden a veces con los Constructores. ${ }^{16}$

Estos dos elementos [escaleras y ascensores], surgidos de una peligrosa descomposición analítica del lugar del habitar, son hasta tal punto ajenos a la estructura habitable, que cada vez con más frecuencia se ven expulsados del espacio de la vivienda. La escalera, desde siempre disociada del habitar, supone en numerosos casos (escuelas, inmuebles, hospitales, etcétera) el espacio peligroso, el lugar de las pesadillas. ${ }^{17}$

Lugar onírico que bebe del imaginario colectivo y de la tecnología como monstruo que destrozará a la humanidad, pero a la vez de la tecnología como única posibilidad de salvación y de conservación de lo bumano (y no solo como forma epistémica de relacionarse con el mundo, sino también como forma de existencia históricamente situada y orientada hacia una posibilidad de futuro).

Para concluir y repasando lo dicho podemos pensar que el mundo de Blame! es una metáfora de la psique y que todo el viaje de Killy es un viaje por la parte inconsciente de esa psique, como si la relación dialógica entre consciencia e inconsciencia se hu-

${ }^{14}$ Ibid., p. 24.

15 Idem.

${ }_{16}$ Nombre que se les da a las máquinas que se dedican a reparar los desperfectos que localizan en la ciudad.

17 Parent, C. Op. cit., pp. 24-25. 
biera roto y alguna función psíquica vagara perdida por la inconsciencia tratando de encontrar una salida. Hay distintos factores que hacen que pensemos en un viaje de descubrimiento psíquico: el camino ascendente, la mónada final, la sensación onírica de muchas secuencias, los monstruos que parecen emerger de fantasías ocultas... Pero no es solo viaje psíquico, es también una crítica que parece emerger del inconsciente colectivo: crítica de la ciudad y de sus espacios de pesadilla, crítica de un sistema económico que genera construcciones infinitas para mantener dinero en circulación. Y es también una propuesta de recorrido, una forma de recorrer todo ese mundo psíquico y también metafóricamente real tratando de mantener una ética y un punto de vista determinado, tomando partido cuando hay que tomarlo y buscando trazar un camino que permita movernos con libertad, aunque a veces haya que destruir las construcciones para conseguir esa libertad de movimientos; todo para recuperar la humanidad en un medio deshumanizado y completamente artificial. Este medio es una metáfora de la modernidad y de la escisión en la que viven los hombres y las mujeres modernas, y Killy se convierte así en símbolo de esta escisión y de la búsqueda de una síntesis que nos permita seguir habitando el mundo, más allá de la circulación interrumpida y desesperanzada, en una recuperación del fluir psíquico y del sentido vital. 


\section{BibLIOGRAFÍA}

Harvey, D. Ciudades rebeldes. Del derecho de la ciudad a la revolución urbana. Madrid, Akal, 2013.

Morey, M. Lectura de Foucault. Madrid, Sexto Piso, 2014.

Ninei, T. Blame! 1. Barcelona, Glénat, 2001.

-Blame! 2. Barcelona, Glénat, 2001.

-Blame! 3. Barcelona, Glénat, 2001.

-Blame! 4. Barcelona, Glénat, 2002.

-Blame! 5. Barcelona, Glénat, 2002.

-Blame! 6. Barcelona, Glénat, 2002.

-Blame! 7. Barcelona, Glénat, 2002.

-Blame! 8. Barcelona, Glénat, 2003.

-Blame! 9. Barcelona, Glénat, 2003.

-Blame! 10. Barcelona, Glénat, 2004.

Parent, C. Vivir en lo oblicuo. Barcelona, Gustavo Gili, 2009.

Virilio, P. Estética de la desaparición. Barcelona, Anagrama, 1988. 